\title{
Experimental Investigation of Methanol Conversion Factor to Formaldehyde in a Pilot Reactor
}

\author{
Mojtaba Zarei ${ }^{1}$, Nader Mokhtarian ${ }^{1 *}$, Farshad Farahbod ${ }^{2}$ \\ ${ }^{I}$ Department of Chemical Engineering, Shahreza Branch, Islamic Azad University, Shahreza, Iran \\ ${ }^{2}$ Department of Chemical Engineering, Firoozabad Branch, Islamic Azad University, Firoozabad, Iran
}

*Corresponding Author: Nader Mokhtarian Department of Chemical Engineering, Shahreza Branch, Islamic Azad University, Shahreza, Iran

\begin{abstract}
Formaldehyde is considered as the natural organic material with the equation of $\mathrm{CH} 2 \mathrm{O}(\mathrm{H}-\mathrm{CHO})$ and the simplest form of aldehydes; in respect of the way, Formaldehyde is one the major significant precursors to numerous types of chemical components. The objectives of this comprehensive study is the methanol oxidation and its conversion to formaldehyde have been experimentally investigated. To do this water and methanol are used as two strategic components in chemical industries and, the feed stream is used to produce formaldehyde in a pilot reactor. Subsequently, due to the presence of water and oxygen in the process of methanol oxidation, the conversion factor has a dramatic increase from 50 percent to approximately 75 in the length of catalytic bed.
\end{abstract}

Keywords: Formaldehyde; Methanol Oxidation; Conversion factor; Pilot Reactor; Catalytic Bed

\section{INTRODUCTION}

One of the formaldehyde production methods in petrochemical industries is the partial oxidation of methanol to formaldehyde which administered a silver catalyst at a temperature range of 110 to 700 degrees centigrade in a fluid bed reactor. Since then, evaporated methanol with air enters the reactor and after passing through the silver bed at the end of reactor enters a heat exchanger that hot gases are cooled in this exchanger. In the last 60 to 70 years, numerous researches with grasping the importance of catalysts, especially metal catalysts in production of chemicals materials in industrial sizes have been widely reported in literature [1-8]. Performing chemical processes using metal catalysts has been considered due to the less cost of operational design in industrial sizes; due to the fact that they are in more suitable conditions in terms of temperature and pressure. Nowadays, a wide range of chemical materials are produced by catalytic conversion process for industrial purposes [9-15].

Several methods have been proposed for production of formaldehyde by oxidation of hydrocarbon gases, that is to say that, increasing formaldehyde levels is also done by these processes. In addition, it was observed that hydrocarbon formaldehyde is usually obtained from detergents such as dilute solutions that are not economically concentrated. It is also stated that obtaining free formaldehyde from other aldehydes and lateral products is difficult. However, despite high problems, improvements have been achieved according to use of special crystals and better control methods. Problems of hydrocarbon oxidation have been studied since the early nineteenth century, but development of practical methods for production of formaldehyde by methods of this type is surrounded by numerous problems. Therefore, studies on methane oxidation show that methane with significant amount under $600{ }^{\circ} \mathrm{C}$ does not oxidize, while, as already mentioned, formaldehyde begins to decompose at temperatures below this. Formaldehyde is used because of elimination of bacteria as an antiseptic solution [16-19].

\section{Materials And Methods}

In the oxidation method through two processes, formaldehyde is produced. The first method is process based on methanol balance, which has an incomplete conversion rate. The second method, which is very common, is the process based on water balance, which is accompanied by water injection into the reactor. This method has a higher conversion percent of methanol to formaldehyde. In this study, reactor based on water balance is studied with a silver bed. Re actions occurring in reactor are divided into two main and subsidiary categories. The main reaction is formaldehyde production from methanol oxidation, Equation 1 shows its mechanism. 


$$
\mathrm{CH} 3 \mathrm{OH}+1 / 2 \mathrm{O}_{2} \rightarrow \mathrm{HCHO}+\mathrm{H}_{2} \mathrm{O}+\Delta \mathrm{H}_{r f}
$$

If the reaction time in reactor is not suitable or operating pressure is too high from standard deviation, then subsidiary and non-useful products such as carbon monoxide, carbon dioxide and dimethyl oxide are produced. The reaction of monoxide and carbon dioxide production occurs in the form of series reactions with the presence of formaldehyde and extra oxygen. Therefore, the amount of oxygen entering reactor also, in addition to the reaction time, it is involved in the production of carbon dioxide and carbon monoxide. Equations 2 and 3 show the production of these two compounds.

$$
\begin{aligned}
& \mathrm{HCHO}+1 / 2 \mathrm{O}_{2} \rightarrow \mathrm{CO}+\mathrm{H}_{2} \mathrm{O}+\Delta \mathrm{H}_{r c o} \\
& \mathrm{CO}+1 / 2 \mathrm{O}_{2} \rightarrow \mathrm{CO}_{2}+\Delta \mathrm{H}_{r \mathrm{rc} 2}
\end{aligned}
$$

As it is known, the reactions are all pyrogenic and cause the temperature of reactor bed to rise. If the amount of methanol entering is not set, its extra amount in system decomposes into water and dimethyl oxide at generated high temperatures in reactor. Equation 4 shows this mechanism [20,21].

$$
2 \mathrm{CH}_{3} \mathrm{OH} \rightarrow(\mathrm{CH} 3)_{2} \mathrm{O}+\mathrm{H}_{2} \mathrm{O}+\Delta \mathrm{H}_{r D}
$$

Formaldehyde production is the most important use for methanol, accounting for about $40 \%$ of it. The formaldehyde can be prepared by dehydrogenation method which is endothermic and referred it above or by methanol oxidation method that is pyrogenic. Most production methods are based on a mixture of two methods of oxidation-dehydrogenation. In these reactions, the heat required for dehydrogenation is typically guaranteed through oxidation. Air-methanol mixture, with extra methanol pass among an empty bed from silver crystals of several layers to exit a high explosive level that reaction temperature is 600 to $650^{\circ} \mathrm{C}$. Then exhaust gases from the reactor are then rapidly cooled down and enter into an absorber. In absorber, unreacted formaldehyde and methanol are dissolved in water. The resulting solution is recycled to distillation methanol and its methanol is returned and a formaldehyde solution is obtained. Finally, the product is in the range of 86 to 90 percent, and formaldehyde is stored as a solution and sold with a concentration of about 37 percent.

\section{RESUlTS AND DISCUSSION}

\subsection{Evaluation of Dimensionless Geometry of Pilot and its Considerable Influence on the Percentage of Methanol Conversion}

Considering that one of the conditions for increasing or decreasing the process scale without dimensioning the pilot geometry is studied, in this section is referred to dimensionless length of pilot that obtained from length-to-diameter ratio of pilot. The results of the research show that from ratio of about 1.7 to about 4.13 , conversion percent increases from 63.3 to 73.8 . But as shown in figure 1 , with an increasing pilot dimensionless geometry from about 4.13 to 5.5 , increasing conversion percentage is not significant. Therefore, the results of this section indicate that increasing dimensionless geometry of pilot cannot always increase the percentage conversion of methanol to formaldehyde. Since the increase of dimensionless geometry can change operational conditions of temperature and pressure as well as pilot areas of dead. The percentage conversion in this reaction in non-dimensional lengths will result in uniformity of percentage change.

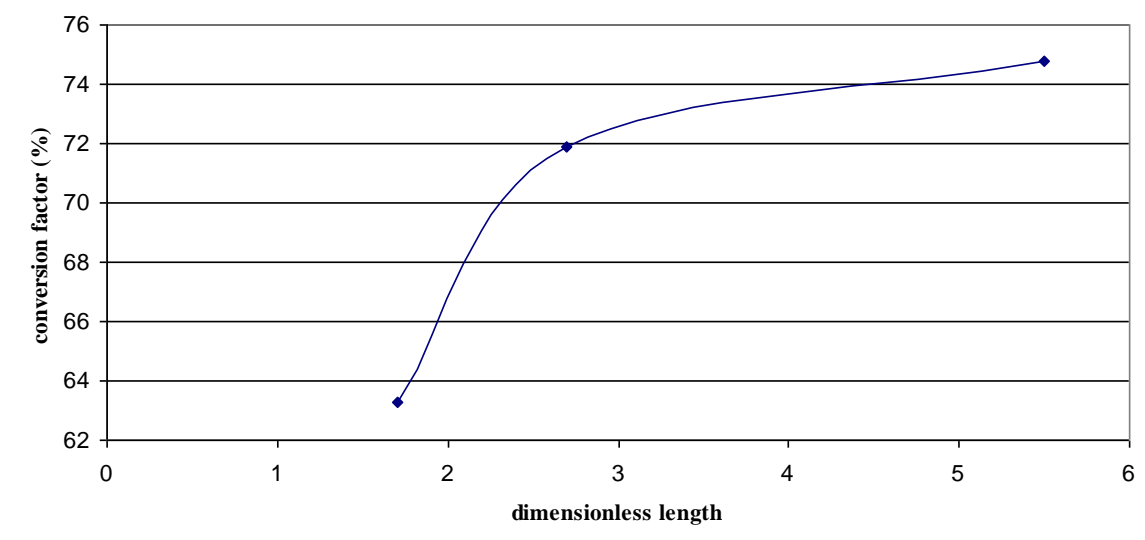

Figure1. Investigating the effect of dimensionless length on the methanol conversion factor 


\subsection{Investigating the Effect of Thermal Profile of Inlet Flow to the Reactor}

As shown in figure 2, the temperature profile is shown along the pilot catalyst bed to convert methanol to formaldehyde. The results indicate that flow temperature of inside reactor is decreasing throughout catalytic bed, which could be due to the development of feed flow and product during the pilot reactor, as well as increasing energy dissipation in the form of viscous dispositions, as well as conduction and displacement mechanisms and transferring heat from inside the pilot to the its outside.

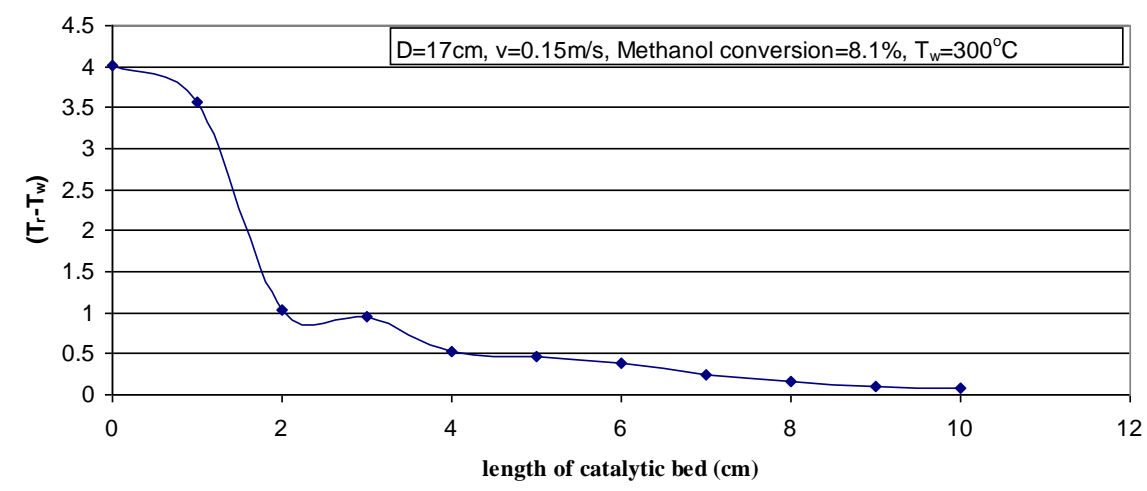

Figure2. Effect of thermal profile of inlet flow to the reactor

\subsection{Study of Relationship between Flow Development and Conversion Percent of Methanol to Formaldehyde}

As shown in figure 3, relationship between flow development and conversion percent of methanol to formaldehyde is expressed. The results indicate that by increasing the bed length, the flow development, as well as the contact time between feed flow and catalyst increases, resulting in increase in conversion percent of methanol to formaldehyde. In this case, percentage of conversion of products such as carbon dioxide and carbon monoxide is reduced.

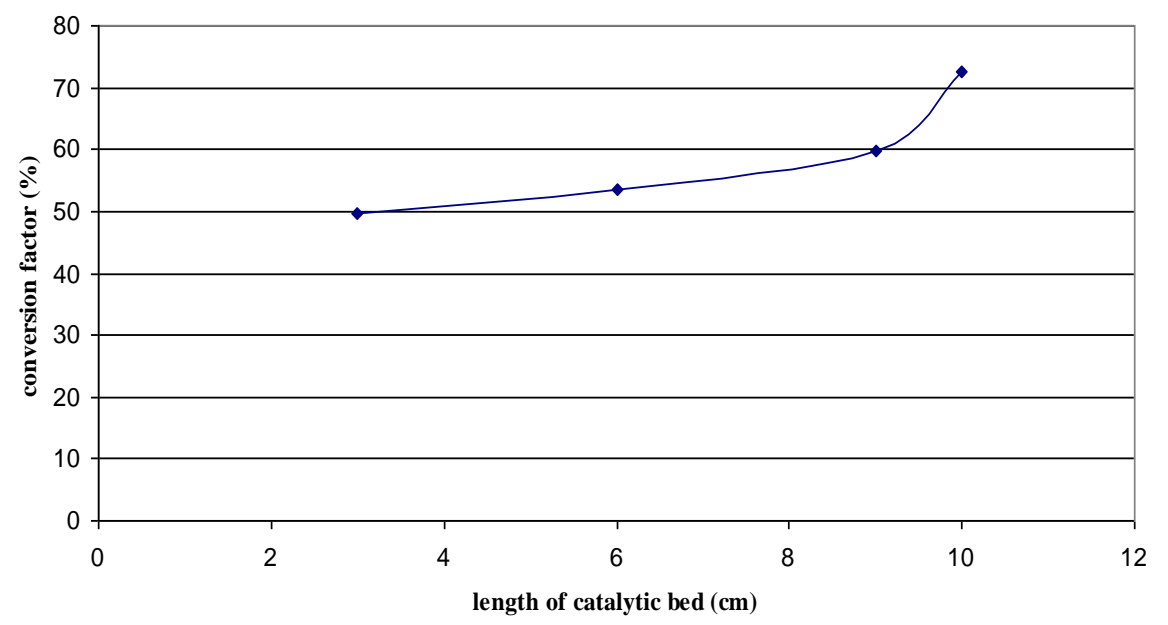

Figure3. Investigating the effect of methanol conversion in the length of catalytic bed

\section{CONCLUSiON}

The profound impact of such parameters like overall equivalence ratio, injection timing, thermal profile on the methanol conversion factor are considered as the major principles of petrochemical industries in the coming decades. The main purpose of this experimental investigation is to operate the significant role of chemical kinetics reaction in the presence of water and oxygen in the oxidation of methanol; that is to say that, regarding the increased the length of the reactor by initiating the process from the beginning times, the conversion factor is increased dramatically in the length of catalytic bed. Thereby, it indicates that the volume of formaldehyde which is produced by the methanol conversion is increased during the length of reactor and it would be an economic revolution in the large scale evaluation in petrochemical industries. 


\section{REFERENCES}

[1] Yan, Z., et al., Enhanced formaldehyde oxidation on CeO 2/AlOOH-supported Pt catalyst at room temperature. Applied Catalysis B: Environmental, 2016. 199: p. 458-465.

[2] Zhu, L., et al., Long- term (2005-2014) trends in formaldehyde (HCHO) columns acrossNorth America as seen by the OMI satellite instrument: Evidence of changing emissions of volatile organic compounds. Geophysical Research Letters, 2017.

[3] Reese, M., et al., Performance of a small-scale Haber process. Industrial \& Engineering ChemistryResearch, 2016. 55(13): p. 3742-3750.

[4] Futagoishi, T., et al., Encapsulation and Dynamic Behavior of Methanol and Formaldehyde inside OpenCage C60 Derivatives. Angewandte Chemie, 2017. 129(10): p. 2802-2806.

[5] Huang, Y., et al., Bifunctional catalyticmaterial: An ultrastable and high-performance surface defect CeO 2 nanosheets for formaldehyde thermal oxidation and photocatalytic oxidation. Applied Catalysis B: Environmental, 2016. 181: p. 779-787.

[6] Rungtaweevoranit, B., et al., Copper NanocrystalsEncapsulated in Zr-based Metal-Organic Frameworks for Highly Selective CO2 Hydrogenation to Methanol. Nano letters, 2016. 16(12): p. 7645-7649.

[7] Liu, J., et al., Numerical study of formaldehyde and unburned methanol emissions of direct injection sparkignition methanol engine under cold start and steady state operating conditions. Fuel, 2017. 202: p. 405-413.

[8] Oestreich, D., et al., Reaction kinetics and equilibrium parameters for the production of oxymethylene dimethyl ethers (OME) from methanol andformaldehyde. Chemical Engineering Science, 2017. 163: p. $92-$ 104.

[9] Sadhukhan, M., et al., Highly dispersed platinum nanoparticles on graphitic carbon nitride: A highly active and durable electrocatalyst for oxidation of methanol, formic acid and formaldehyde. International Journal of Hydrogen Energy, 2017. 42(15): p. 9371-9383.

[10] Gribovskii, A., et al., Microchannel reactor for intensifying oxidation of methanol to formaldehyde over $\mathrm{Fe}$ Mo catalyst. Chemical Engineering Journal, 2017. 308: p. 135-141.

[11] Liu, H., et al., Interpretation and prediction of the vapor-liquid equilibrium of formaldehyde-watermethanol ternary system by the conductor-like screening model for real solvents. Fluid Phase Equilibria, 2016. 429: p. 233-241.

[12] Schmitz, N., et al., Liquid-liquid equilibrium in binary and ternary mixtures containing formaldehyde, water, methanol, methylal, and poly (oxymethylene) dimethyl ethers. Fluid Phase Equilibria, 2016. 425: p. 127-135.

[13] Shan, J., et al., Water co-catalyzed selective dehydrogenation of methanol to formaldehyde and hydrogen. Surface Science, 2016. 650: p. 121-129.

[14] Nikolenko, N., et al., Preparation of iron molybdate catalysts for methanol to formaldehyde oxidation based on ammonium molybdoferrate (II) precursor. Journal of Saudi Chemical Society, 2016.

[15] Raoof, J.-B., S.R. Hosseini, and S. Rezaee, A simple and effective route for preparation of platinum nanoparticle and its application for electrocatalytic oxidation of methanol and formaldehyde. Journal of MolecularLiquids, 2015. 212: p. 767-774.

[16] Alonso-Buenaposada, I.D., et al., Effect of methanol content in commercial formaldehyde solutions on the porosity of RF carbon xerogels. Journal of Non-Crystalline Solids, 2015. 426: p. 13-18.

[17] Ozbek, M.O. and J.H .Niemantsverdriet, Methane, formaldehyde and methanol formation pathways from carbon monoxide and hydrogen on the (001) surface of the iron carbide $\chi$-Fe 5 C 2. Journal of Catalysis, 2015. 325: p. 9-18.

[18] Albrecht, L. and R.J. Boyd, Atomic energy analysisof cooperativity, anti-cooperativity, and noncooperativity in small clusters of methanol, water, and formaldehyde. Computational and Theoretical Chemistry, 2015. 1053: p. 328-336.

[19] Dias, A.P.S., et al., The role of the suprastoichiometric molybdenumduring methanol to formaldehyde oxidation over Mo-Fe mixed oxides. Journal of Molecular Catalysis A: Chemical, 2015. 397: p. 93-98.

[20] Redondo, A.B., et al., Formaldehyde, methanol and methyl formate from formic acid reaction over supported metal catalysts. Catalysis Communications, 2014. 56: p. 128-133.

[21] Raoof, J.-B., S.R. Hosseini, and S. Rezaee, Preparation of Pt/poly (2-Methoxyaniline)-sodium dodecyl sulfate composite and its application for electrocatalytic oxidation of methanol and formaldehyde. Electrochimica Acta, 2014. 141: p. 340-348. 


\section{AUTHORS' BIOGRAPHY}

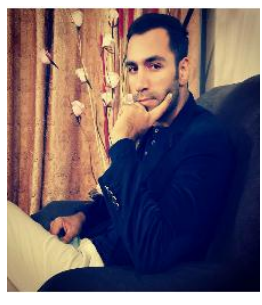

Mojtaba Zarei, Master degree of Chemistry Engineering at Islamic Azad University, Shahreza Branch, Iran. My current interests in Chemistry engineering sciences include a full-field study of Data Gathering, Process Simulation, and Enhanced Oil Recovery Methods. As a Chemistry Engineer, I systematically used my knowledge and experience to analyze the situation and then define, design and implement a method to reduce the environmental effects by reducing the unnecessary burning of gases at the flares.

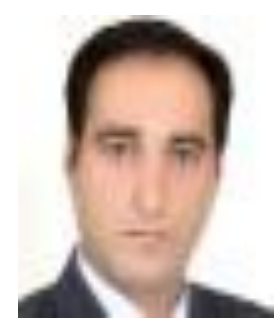

Dr. Nader Mokhtarian, is Associate Professor and M.SC. and doctoral student supervisor, and head of Department of Chemical Engineering at Islamic Azad University, Shahreza Branch, Iran, where he specializes in different substrate on performance of microbial fuel cell, Designation of advanced Reactors in petrochemical industries and, Joule Heating Effect on Electroosmotic Flow (Analytical Approach). He managed several research projects for the Department of Chemical Engineering at Islamic Azad University, Shahreza Branch. To date, Dr. Mokhtarian has published more than 30 journal and conference papers.

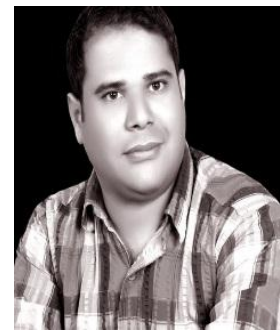

Dr. Farshad Farahbod, is an assistant professor in chemical engineering. The field of his studies is environmental problems, design of chemical engineering process, design of novel evaporators, renewable energies etc...

Citation: Mojtaba Zarei et.al., (2018). Experimental Investigation of Methanol Conversion Factor to Formaldehyde in a Pilot Reactor, International Journal of Petroleum and Petrochemical Engineering (IJPPE), 4(1), pp.82-86, DOI: http://dx.doi.org/10.20431/2454-7980.0401009

Copyright: (C) 2018 Mojtaba Zarei, (2018). This is an open-access article distributed under the terms of the Creative Commons Attribution License, which permits unrestricted use, distribution, and reproduction in any medium, provided the original author and source are credited 